\title{
Progress in Physical Geography
}

http://ppg.sagepub.com

Remote sensing and the future of landscape ecology

Adrian C. Newton, Ross A. Hill, Cristian Echeverría, Duncan Golicher, José M. Rey Benayas, Luis Cayuela and Shelley A. Hinsley

Progress in Physical Geography 2009; 33; 528

DOI: $10.1177 / 0309133309346882$

The online version of this article can be found at:

http://ppg.sagepub.com/cgi/content/abstract/33/4/528

Additional services and information for Progress in Physical Geography can be found at:

Email Alerts: http://ppg.sagepub.com/cgi/alerts

Subscriptions: http://ppg.sagepub.com/subscriptions

Reprints: http://www.sagepub.com/journalsReprints.nav

Permissions: http://www.sagepub.co.uk/journalsPermissions.nav

Citations http://ppg.sagepub.com/cgi/content/refs/33/4/528 
Progress in Physical Geography 33(4) (2009) pp. 528-546

\title{
0
}

\section{Remote sensing and the future of landscape ecology}

\section{Adrian C. Newton, ${ }^{\prime *}$ Ross A. Hill, ${ }^{,}$Cristian Echeverría, ${ }^{2}$ Duncan Golicher, José M. Rey Benayas, ${ }^{3}$ Luis Cayuela ${ }^{3,4}$ and Shelley A. Hinsley ${ }^{5}$}

'School of Conservation Sciences, Bournemouth University, Talbot Campus, Poole BH12 5BB, UK

${ }^{2}$ Departamento Manejo de Bosques y Medio Ambiente, Facultad de Ciencias Forestales, Universidad de Concepción, Casilla 160-C, Concepción, Chile ${ }^{3}$ Departamento de Ecología, Universidad de Alcalá, 28871 Alcalá de Henares, Spain ${ }^{4}$ Departamento de Ecología, Centro Andaluz de Medio Ambiente, Universidad de Granada, Junta de Andalucía, Avenida del Mediterráneo S/N, 18006, Granada, Spain

${ }^{5}$ Centre for Ecology and Hydrology, Maclean Building, Benson Lane, Crowmarsh Gifford, Wallingford OX10 8BB, UK

\begin{abstract}
Landscape ecology focuses on the analysis of spatial pattern and its relationship to ecological processes. As a scientific discipline, landscape ecology has grown rapidly in recent years, supported by developments in GIS and spatial analysis techniques. Although remote sensing data are widely employed in landscape ecology research, their current and potential roles have not been evaluated critically. To provide an overview of current practice, 438 research papers published in the journal Landscape Ecology for the years 2004-2008 were examined for information about use of remote sensing. Results indicated that only $36 \%$ of studies explicitly mentioned remote sensing. Of those that did so, aerial photographs and Landsat satellite sensor images were most commonly used, accounting for $46 \%$ and $42 \%$ of studies, respectively. The predominant application of remote sensing data across these studies was for thematic mapping purposes. This suggests that landscape ecologists have been relatively slow to recognize the potential value of recent developments in remote sensing technologies and methods. The review also provided evidence of a frequent lack of key detail in studies recently published in Landscape Ecology, with 75\% failing to provide any assessment of uncertainty or error relating to image classification and mapping. It is suggested that the role of remote sensing in landscape ecology might be strengthened by closer collaboration
\end{abstract}

*Author for correspondence. Email: anewton@bournemouth.ac.uk

(C) The Author(s), 2009. Reprints and permissions:

DOI: $10.1177 / 0309133309346882$

http://www.sagepub.co.uk/journalsPermissions.nav 
between researchers in the two disciplines, by greater integration of diverse remote sensing data with ecological data, and by increased recognition of the value of remote sensing beyond land-cover mapping and pattern description. This is illustrated by case studies drawn from Latin America (focusing on forest loss and fragmentation) and the UK (focusing on habitat quality for woodland birds). Such approaches might improve the analytical and theoretical rigour of landscape ecology, and be applied usefully to issues of outstanding societal interest, such as the impacts of environmental change on biodiversity and ecosystem services.

Key words: biodiversity conservation, ecosystem services, Landsat, spatial dynamics, theory.

\section{Introduction}

Landscape ecology focuses on the analysis of spatial pattern and its relationship to ecological processes, at a variety of scales $(\mathrm{Wu}$, 2006). Landscapes can be defined as areas that are spatially heterogeneous, and therefore landscape ecology approaches can potentially be applied at a range of scales to a wide range of different environments, including terrestrial, aquatic and marine systems (Turner, 2005; Wu and Hobbs, 2007). Major research themes in landscape ecology include the causes and consequences of spatial pattern in landscapes, the effects of disturbance, ecological flows in landscape mosaics, land-use and land-cover change, and landscape conservation and sustainable management (Forman, 1995; Turner et al., 2001; Wu and Hobbs, 2002; 2007; Turner, 2005). As a research endeavour, landscape ecology has grown rapidly in recent decades (Wu, 2007), supported by the development of specialist journals (eg, Landscape Ecology) and academic organizations (eg, the International Association for Landscape Ecology, IALE, http://www.landscape-ecology.org).

Landscape ecology studies often employ remote sensing data together with field measurements, and undertake geospatial analyses (using Geographical Information Systems, GIS) or simulation modelling (Turner, 2005). The development of landscape ecology as a discipline has been particularly stimulated by technological developments in remote sensing and GIS; in fact its origins lie in the development of aerial photography (Groom et al., 2006). As with many areas in physical geography and interrelated fields, remote sensing is a key technology for quantifying landscape patterns and processes in the twenty-first century. The interpretation and classification of data generated from remote sensors has matured as a discipline with a growing specialist literature. The remote sensing community has developed a rich and varied set of analytical tools that go well beyond traditional cartographic products.

However, it is not clear how far these innovative methods and products have been integrated within landscape ecology. In a recent review of the state of the science, for example, Turner (2005) accords remote sensing little more than a passing mention. Although Frohn (1998) provided an overview of the use of remote sensing data in landscape ecology, the account focused largely on the calculation of landscape pattern metrics. More recently, Groom et al. (2006) highlighted the potential value of recent technical developments including multi-angle viewing, hyperspectral sensing and radar, to European landscape ecology, but did not examine the extent to which these approaches have been adopted by researchers. Given these and other recent developments, it is pertinent to consider the current and potential role of remote sensing in landscape ecology.

This paper provides an overview of the use of remote sensing data in recent landscape ecology research, with the aim of evaluating experience obtained to date. Rather than focus solely on methodological developments, however, consideration is also given to the development of landscape ecology as a scientific discipline. This reflects 
the concerns that have repeatedly been raised that landscape ecology is conceptually and theoretically weak. For example, in an early review of published studies, Wiens (1992) found that most research was predominately descriptive, with limited evidence of quantitative analysis or experimentation, and little reference to theory. Subsequent reviews have documented an increased use of quantitative statistical analysis and modelling approaches, but little progress in development of theory (Hobbs, 1997; Andersen, 2008). In her recent review of landscape ecology science, Turner (2005) failed to mention the issue of theory altogether. Here, we explore the contention that quantitative analysis of remote sensing data in combination with field data can strengthen the scientific rigour of landscape ecology, by supporting the testing of hypotheses grounded in relevant ecological theory.

This paper evaluates the recent use of remote sensing in landscape ecology, first through a survey of research publications over the past five years. Selected case studies are then presented that illustrate the potential value of using diverse remote sensing data together with ecological field data, as an integrated approach to landscape ecology research. Finally, the future development of landscape ecology as a predictive scientific discipline is considered, with particular reference to the potential role of remote sensing.

\section{Overview of recent research}

In order to provide a summary of recent research involving application of remote sensing to landscape ecology, a literature review was performed focusing on the journal Landscape Ecology (http://www.springerlink. com). This is the leading scientific journal in the field, produced in association with IALE. All of the scientific papers published in this journal for the last five complete years (ie, 2004-2008 inclusive) were consulted, and examined to ascertain whether remote sensing techniques were employed in the research described. In total, 438 publications were examined, of which 158 (ie, 36\%) mentioned the use of remote sensing techniques in the text. This by itself provides some measure of the use of remote sensing approaches within the discipline. However, while almost two-thirds of investigations did not mention remote sensing methods, many will have made use of geospatial data and mapping derived from remote sensing without having acknowledged this explicitly. Those publications that did directly mention remote sensing were examined in greater depth, and the following information was extracted from each: (1) type of remote sensing data used; (2) type of application of remote sensing data; (3) the spatial extent and location of the study area; (4) the type of ecosystem studied; (5) whether or not classification or interpretation of imagery was performed; and (6) whether data quality issues, data accuracy or uncertainty were explored. Although somewhat generic, these themes capture an overview of applications and approaches.

Results indicated that aerial photographs (orthophotos) and digital imagery acquired from sensors on board the Landsat series of satellites (ie, MSS, TM, ETM+) were by far the most commonly used types of imagery, accounting for $46 \%$ and $42 \%$ of studies, respectively. Imagery acquired by sensors on board other satellite series were employed by a small minority of studies, namely SPOT (eg, HRV, HRG) (3\%), NOAA (AVHRR) $(4 \%)$, IRS (LISS) $(1 \%)$, Ikonos $(1 \%)$ and QuickBird (0.5\%). Only $0.5 \%$ of studies made use of radar data. Finally, $2 \%$ of studies employed multiple sources of remote sensing data (ie, more than two). This is a notable result, indicating that individual image sources tended to be used in isolation within individual studies (although some studies did make use of multiple images from the same source).

Virtually all of the investigations employed remote sensing techniques in support of some kind of mapping activity, principally for mapping landscape pattern or spatial structure. In approximately 14\% of studies, 
remotely sensed data were used as input to some kind of environmental model, although most studies employed analytical statistical methods. Very few studies (approximately $3 \%$ ) were explicitly designed to develop or refine remote sensing techniques - for example, the development of new approaches to image analysis or classification.

Investigations were undertaken at a wide range of scales, ranging from site-based studies of less than $1 \mathrm{~km}^{2}$ in extent to regionalor national-scale investigations extending $>100,000 \mathrm{~km}^{2}$ in area. Most studies (ie, 63\%) focused on areas between 100 and 100,000 $\mathrm{km}^{2}$, with the modal category being 1000$10,000 \mathrm{~km}^{2}$ (Figure 1). A small number of studies $(<5 \%)$ were undertaken at a range of scales, with the objective of comparing results obtained at different scales. The relationship between spatial extent and image type was not examined in detail, but predictably it was observed that coarse spatial resolution imagery (such as AVHRR) was used for study areas of relatively large spatial extent.

With respect to types of ecosystem (or land cover) examined, around a quarter (26\%) of studies were undertaken in areas where no single ecosystem type predominated. The majority of studies examined one ecosystem type in particular, of which forest was by far the commonest, accounting for $37 \%$ of studies (Figure 2). Many ecosystem types, such as coastal or marine, wetland or freshwater, were poorly represented within the sample of publications, each accounting for $\leq 4 \%$ of studies (Figure 2). Overall, most studies

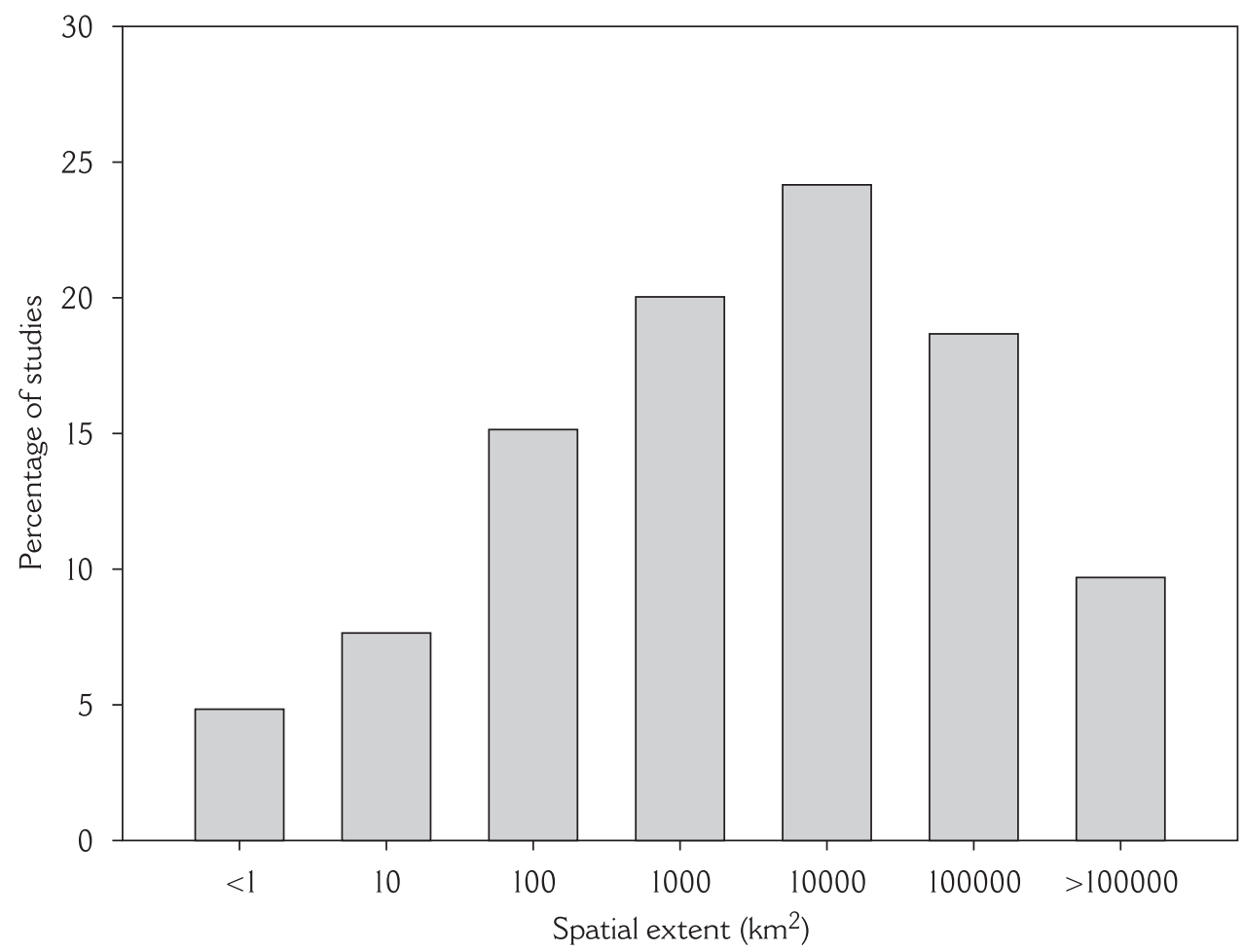

Figure 1 Spatial extent of 158 research investigations that employed remote sensing imagery, surveyed from the journal Landscape Ecology for the years 2004-2008 (inclusive). The $x$ axis values refer to categories, namely $<1 \mathrm{~km}^{2}, 1-10 \mathrm{~km}^{2}, 10-100 \mathrm{~km}^{2}$, $100-1000 \mathrm{~km}^{2}, 1000-10,000 \mathrm{~km}^{2}, 10,000-100,000 \mathrm{~km}^{2}$ and $>100,000 \mathrm{~km}^{2}$ 


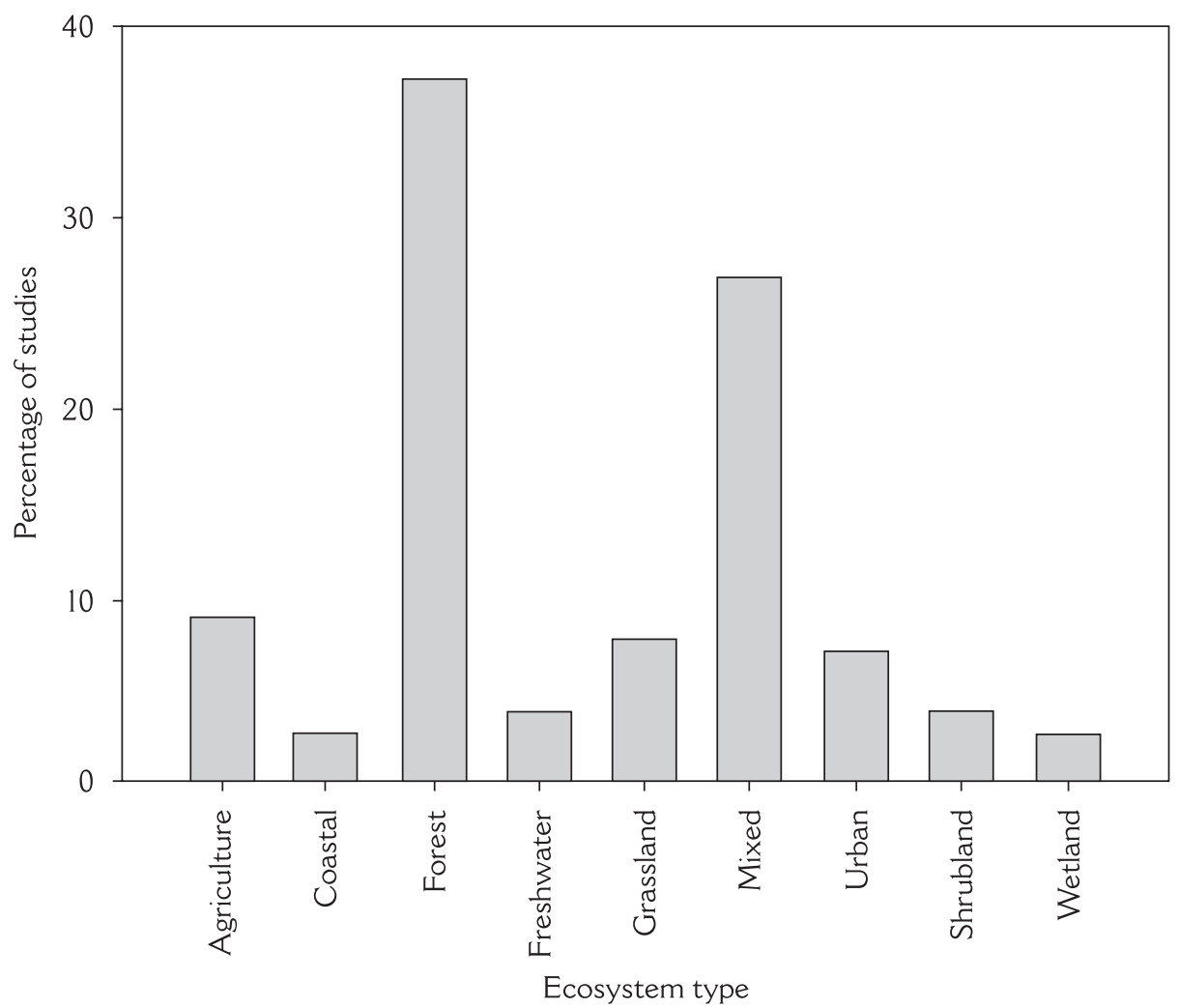

Figure 2 The different types of ecosystem (or land cover) examined in 158 research investigations that employed remote sensing imagery, surveyed from the journal Landscape Ecology for the years 2004-2008 (inclusive). The categories refer to the predominant ecosystem type in the study areas concerned. The category 'Mixed' refers to situations where no single ecosystem or land-cover type predominated

(ie, 63\%) performed some kind of interpretation or classification of remote sensing imagery, of which the most common approach was visual interpretation of orthophotos. However, the methods employed in image analysis were often not described in detail, and were in some cases omitted altogether. In addition, a majority of studies (ie, $75 \%$ ) failed to provide any assessment of uncertainty or error relating to image analysis or classification.

It is recognized that the sample of publications considered here is biased, having focused on a single journal (ie, Landscape Ecology) over a restricted time period. Other journals might have provided a very different set of results, reflecting variation in editorial emphasis and the refereeing process. In particular, journals with a specific focus on remote sensing (such as Remote Sensing of the Environment and International Journal of Remote Sensing) tend to be associated with greater emphasis on the technical aspects of image analysis. Publications in these journals may therefore be expected to demonstrate more developmental approaches to remote sensing (including methods and data types). (For a recent overview of current developments in ecological applications of remote sensing, see Muchoney, 2008.) Both remote sensing and landscape ecology now fall within the scope of a great many journals. This is 
illustrated by an online search of the ISI Web of Knowledge (http://www.isiknowledge.com) using 'remote sensing' and 'landscape ecology' as search terms, which identified 136 papers published between 2004 and 2008, spread among more than 60 journals. However, the purpose here was to examine the use of remote sensing explicitly by the landscape ecology research community, and therefore the review was restricted to the leading journal of the discipline.

In the literature reviewed, most investigations focused on the use of land-cover maps as a basis for analysing landscape pattern. In many cases, these maps were ultimately derived from remote sensing imagery, but the source of such imagery was not always made explicit. Even in cases where image sources were referred to, the information provided was often very limited. For example, more than $20 \%$ of studies failed to report the resolution characteristics of the remote sensing data that were employed.

Results from this survey suggest that landscape ecologists are rather conservative in their use of remote sensing data. This is perhaps surprising given the emphasis on development of novel spatial analysis methods that has characterized research in this area. Remote sensing technologies continue to develop rapidly, including relatively novel techniques such as ground-based and airborne radar and LiDAR sensors, airborne digital hyperspectral scanners, frame cameras and videography (Wulder and Franklin, 2003; Groom et al., 2006; Newton, 2007a). On the evidence presented here, these techniques have yet to have any significant impact on landscape ecology as presented in the discipline's leading journal. A particularly surprising finding was how few studies have employed very high spatial resolution digital image data from space-borne platforms, such as QuickBird and Ikonos, which now offer imagery with spatial resolutions of less than $5 \mathrm{~m}$. These would appear to have particular value for landscape ecology (Groom et al., 2006), but have apparently been relatively little employed to date. Even less apparent in this search was the use of high spatial resolution digital image data from airborne platforms (eg, using sensors such as ATM, AVIRIS or CASI). This supports the suggestion made by Aplin (2005) that ecologists generally seem reluctant to adopt new approaches and remote sensing data types. Interestingly, Aplin (2005) also noted that remote sensing specialists 'have perhaps focussed on technological issues as their principal concern, rather than ecological problems', highlighting a potential divide between these different research communities.

From this survey, landscape ecology emerges as a discipline that is preoccupied with analysing thematic maps, but is perhaps less concerned with reporting how they are produced. There are numerous sources of error or uncertainty with producing landcover maps from remote sensing imagery. These can include position error (ie, inaccurate placement of a feature or object on a map), thematic error (when an object or feature on a map is identified incorrectly) or uncertainty pertaining to class nomenclature. Estimation of such errors and acknowledgement of uncertainty is an essential part of quality control and should form part of any mapping project using remote sensing data (Iverson, 2007; Shao and $\mathrm{Wu}, 2008)$. Accuracy estimates of $80 \%$ or less are common for land-cover maps produced from remote sensing imagery (Newton, 2007a). Given this, the fact that most studies failed to report directly on any assessment of uncertainty relating to image classification represents a serious limitation of much of the current research reviewed here. It is acknowledged that many studies will have made use of thematic maps derived from remote sensing that are reported on elsewhere, but nonetheless these studies have failed to transfer key information on uncertainty, which is a significant omission.

Significantly, those studies that provided an evaluation of potential sources of 
error were typically those that involved image classification as part of the reported investigation. This highlights the potential value of close collaboration between landscape ecologists and remote sensing specialists. It is recognized that there are many examples of remote sensing methods being applied successfully and rigorously to landscape ecology research, including studies published in many journals other than that reviewed here. However, it has been noted previously that there has traditionally been a divide among the remote sensing and ecological science research communities (Turner et al., 2003; Aplin, 2005; McDermid et al. 2005). The current review provides further evidence of this divide, with specific reference to landscape ecology.

The following case studies provide examples of research investigations that have attempted to bridge this divide, by integrating analysis of remote sensing data with ecological field data. These case studies also adopted a hypothesis-testing framework, with the aim of contributing to the development of landscape ecology theory.

\section{Use of remote sensing in landscape ecology: case studies}

1 Forest loss and fragmentation in Latin America A variety of remote sensing images and analytical approaches have been used to examine the rates and patterns of loss and fragmentation of native forests in each of four study areas in Mexico and Chile (Newton, 2007b). In addition, the influence of social and environmental factors responsible for causing changes in forest cover were analysed, as well as the impacts on biodiversity (focusing on the composition and species richness of the woody plant flora). This case study therefore provides a relatively rare example of an integrated approach to landscape ecology research, involving analysis of both environmental pressures and impacts, as well as landscape pattern. In addition, the research involved the analysis and interpretation of remote sensing imagery as an integral part of the overall approach, enabling the image classification to be based on an ecological understanding of the study areas, and to be orientated to what was required in terms of analysing the ecological dynamics of landscapes.

In Chile, research focused on the temperate rain forest zone in the south of the country. This area has been classified as a global priority for biodiversity conservation (Newton, 2007b). To analyse changes in forest area and spatial pattern over time, a set of three Landsat scenes was acquired for the years 1975 (MSS), 1990 (TM) and 2000 (ETM+) (Figure 3). Each image was classified using a maximum likelihood algorithm into crop and pasture land, shrubland and arboreous shrubland, native forest, and exotic tree plantation. A postclassification filter was applied to establish a minimum mappable unit of 0.45 ha. Accuracy of each map was assessed using either aerial photographs (from 1999) or 226 field records (acquired in 2002-2003) (Echeverría et al., 2006). Overall agreement of classification was $83 \%$ for the 1975 MSS image, $83 \%$ for the 1990 TM image, and $85 \%$ for the 2000 ETM+ image. The lowest values of accuracy corresponded to shrubland, arboreous shrubland and native forest categories. These three formations are very similar in their spectral signatures (Bhattacharrya distance less than 1.9), because they correspond to stages in a continuous succession process. It was found that supporting data from other studies and control points were important to distinguish these stages of forest succession (Echeverría et al., 2006).

The forest-cover maps derived from the remote sensing imagery were then analysed using a range of commonly used pattern metrics (ie, patch size, shape, connectivity, isolation and interior forest area; Figure 4), which were then related to measures of species diversity, richness, species composition, forest structure and anthropogenic disturbances (Echeverría et al., 2007). 


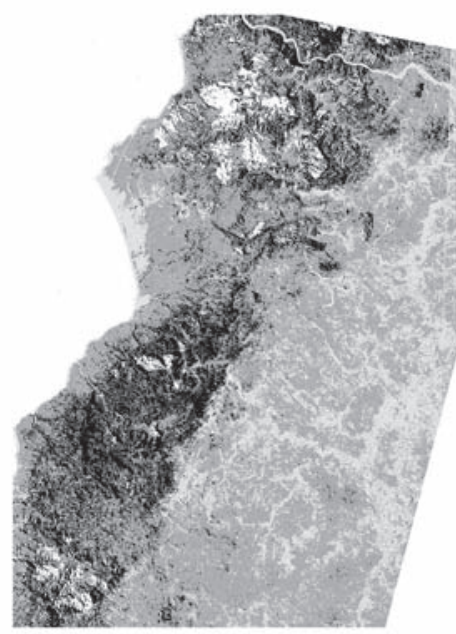

(a)

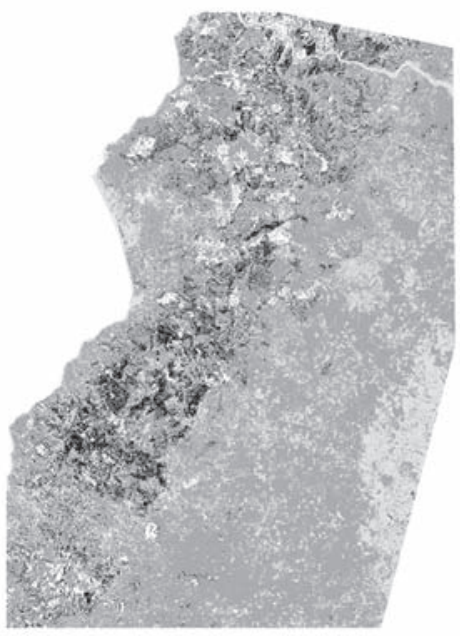

(b)

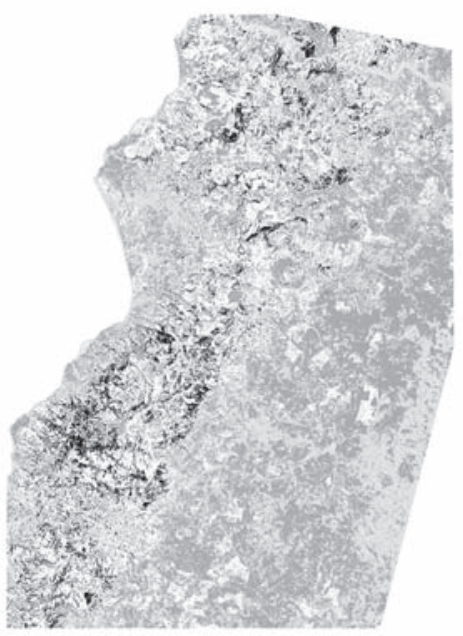

(c)

Figure 3 Major land-cover types in Rio Maule-Cobquecura, Chile, for the years (a) 1975, (b) 1990 and (c) 2000. Light grey-crop and pasture land; medium grey-shrubland and arboreous shrubland; black - native forest; white - exotic species plantation

Source: Newton (2007b).

Patch size was found to be the most important attribute influencing different measures of species composition, stand structure and anthropogenic disturbances. The abundance of tree and shrub species associated with interior and edge habitats was also significantly related to variation in patch size, whereas basal area, a measure of forest structure, significantly declined with decreasing patch size. Further research examined the geophysical variables that explained the spatial patterns of forest loss and fragmentation between 1976 and 1999 using both a GIS-based land-use change model (GEOMOD) and spatially explicit logistic regression (Echeverría et al., 2008). Both modelling approaches produced similar results, namely that forest fragmentation occurred mainly from the edges of small fragments situated on gentle slopes and far away from rivers. Results indicated that deforestation is associated with activities such as clearance of forest for pasture and crops and forest logging for fuel wood.
A parallel investigation was undertaken in Mexico, focusing on the Highlands of Chiapas and montane areas of Veracruz. Again, images collected over three decades were analysed, including aerial photographs and Landsat imagery (MSS, TM and ETM+). The forest composition and structure in Chiapas is the result of a complex combination of chronic anthropogenic disturbance (Cayuela et al., 2006a) and climatic effects (Golicher et al., 2008). The focal habitat of greatest conservation concern in the region is species-rich montane cloud forest. This forest type is usually embedded within a surrounding matrix of less diverse disturbed cloud oak forest (Cayuela et al., 2006a). Classification of satellite imagery for the purposes of landscape analysis was found to be particularly difficult, as spectral data alone were insufficient to discriminate between key classification categories (Cayuela et al., 2006c). This affected the calculation of landscape scale metrics. In order to improve the utility of the classification in this context, 
(a)

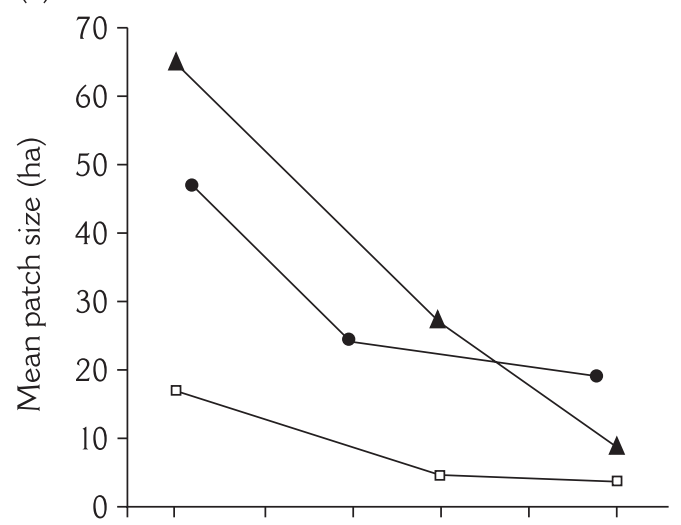

(b)

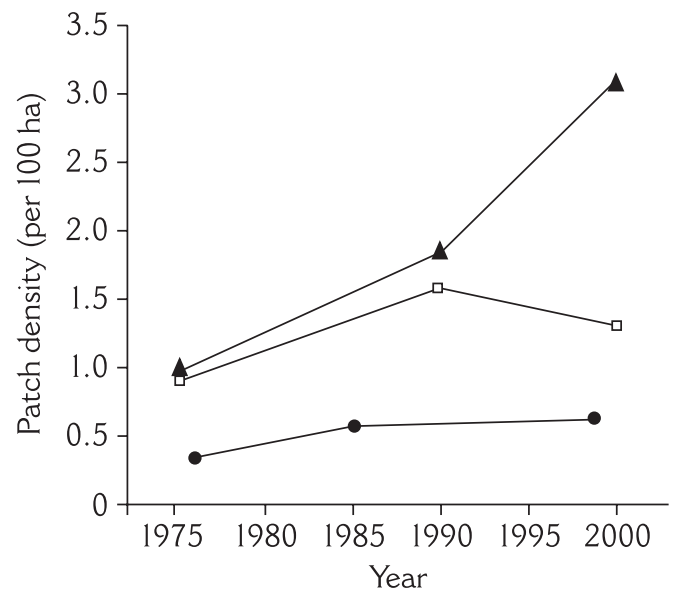

Figure 4 Forest fragmentation in three study areas, estimated from analysis of satellite remote sensing imagery. Two measures of fragmentation are presented: (a) mean patch size; (b) patch density. Symbols: filled circle - Los Muermos (Chile); filled triangle-Chiapas (Mexico); empty square - Maule (Chile). Values were also obtained for Central Veracruz (not illustrated) for two dates, where mean patch size declined from 1176 ha in 1984 to 1291 ha in 2000, and patch density declined from 0.013 to 0.009 over the same period

Source: Newton et al. (2009).

expert knowledge derived from prior studies on landscape properties was incorporated into the classification through the use of an algorithm based on the Dempster-Shafer theory of evidence. The accuracy of the classification was significantly increased, from $59.8 \%$ to $68.6 \%$ (Cayuela et al., 2006c). This allowed the extent and fragmentation of the focal areas of cloud forest to be estimated and confidence intervals to be placed on these quantities based on classification uncertainty (Cayuela et al., 2006a).

The forest-cover maps produced were then analysed in a similar way to those in Chile, involving analysis of the factors responsible for forest loss and fragmentation (Figure 4), and impacts of fragmentation on floristic diversity (Cayuela et al., 2006b; 2006d; 2006e). In contrast to Chile, effects of fragmentation on floristic diversity were not detectable, although within-fragment disturbance was associated with lower tree diversity at a local scale, reflecting loss of latesuccessional species (Cayuela et al., 2006b).

These examples demonstrate the benefits of integrating remote sensing data with ecological field data, to support both quantitative spatial analysis and modelling activities. Incorporation of field data and expert knowledge significantly increased the accuracy of image classification, and enabled the spatial dynamics of land-cover change to be related to impacts on biodiversity. These analyses also provided insights into relevant ecological theory relating to human impacts on forest biodiversity, specifically with respect to phenomena such as habitat fragmentation and edge effects (Newton et al., 2009). For example, in Chile, evidence was found of a positive feedback between the processes of forest fragmentation and anthropogenic disturbance within patches, the latter occurring at higher intensity in smaller patches (Echeverría et al., 2007). Results from both study areas highlighted the value of ecological succession theory to understanding the impacts of habitat fragmentation on forest biodiversity, enabling testable predictions to be made (Newton et al., 2009). These predictions are currently 
being further tested in Latin American dryland forests (Newton, 2008), a global conservation priority (Miles et al., 2006).

\section{Woodland habitat quality in the UK}

A recent study at Monks Wood National Nature Reserve in Cambridgeshire, eastern England, has demonstrated the potential of remote sensing for assessing relationships with ecological data, scaling these up to a landscape level, and making comparisons with other sites. Monks Wood covers 157 ha, and is a lowland site of ancient, semi-natural deciduous woodland. A series of airborne digital data acquisition campaigns since 2000 has resulted in the development and assessment of a suite of derived products. These include: a canopy height model and above-ground carbon content map from leaf-on LiDAR data (Gaveau and Hill, 2003; Patenaude et al., 2004); a National Vegetation Classification map from integrated LiDAR and hyperspectral airborne data (Hill and Thomson, 2005); an overstorey tree species map from time-series multispectral data (Hill et al., 2008); and an understorey canopy height model from leaf-on and leaf-off LiDAR data (Hill and Broughton, 2009).

Habitat quality is a fundamental concept in ecology, but it is difficult to quantify objectively, especially over landscapes. Vegetation structure is a key characteristic of avian habitat, and can play a significant role in influencing habitat quality (Hinsley et al., 2009). At Monks Wood, nestling body mass has been used as a measure of avian breeding performance that is likely to reflect territory quality (Bradbury et al., 2005). This is because nestling body mass combines the effects of food abundance and availability with the adults' abilities to find food (foraging efficiency) and to deliver it to the nestlings (travel costs). Examining data from nestboxes in the breeding season of 2001, mean nestling body mass at 11 days of age increased with mean canopy height in a sample area around the nestbox for Blue Tits Cyanistes caeruleus L., but for Great Tits Parus major L. the relationship was negative (Hinsley et al., 2002). This difference suggested that for this particular breeding season, Great Tit foraging success benefited from a more varied height profile around the nest site than did that of Blue Tits, although many factors could be involved, including competition for food between the two species. Using the relationship between nestling body mass and remotely sensed woodland canopy height, a predictive map of reproductive performance (and hence habitat quality) for Great Tits was generated across the entire woodland (Figure 5) (Hill et al., 2004). The standard error of prediction was $\pm 0.37 \mathrm{~g}$ (or $2.1 \%$ of average Great Tit nestling body mass).

By extending the analysis for Great Tits over a seven-year period during which weather conditions varied, it was demonstrated that the slopes and correlation coefficients of the mass/height relationships were related linearly to an index of spring warmth (the warmth sum). Nestling body mass declined with canopy height in cold, late springs, but increased with height in warm, early springs (Hinsley et al., 2006). The parameters of the mass/height relationships, and the warmth sum, were also related linearly to the winter North Atlantic Oscillation index, but with a timelag of one year in the latter parameter. Therefore, within the same wood, the structure conferring 'best' habitat quality for Great Tits differed between years depending on the weather conditions, and this was shown to be predictable based on the regional-scale climatic drivers.

The spatial distribution of canopy height (as assessed using airborne remote sensing) has thus been shown to be of significance in influencing habitat quality. This approach to habitat modelling is particularly apposite for woodland where the three-dimensional complexity of the habitat limits both the resolution and extent of field-based data collection. However, the influence of canopy structure on habitat quality and occupancy is more complicated than suggested in the simple relationships above. For example, 

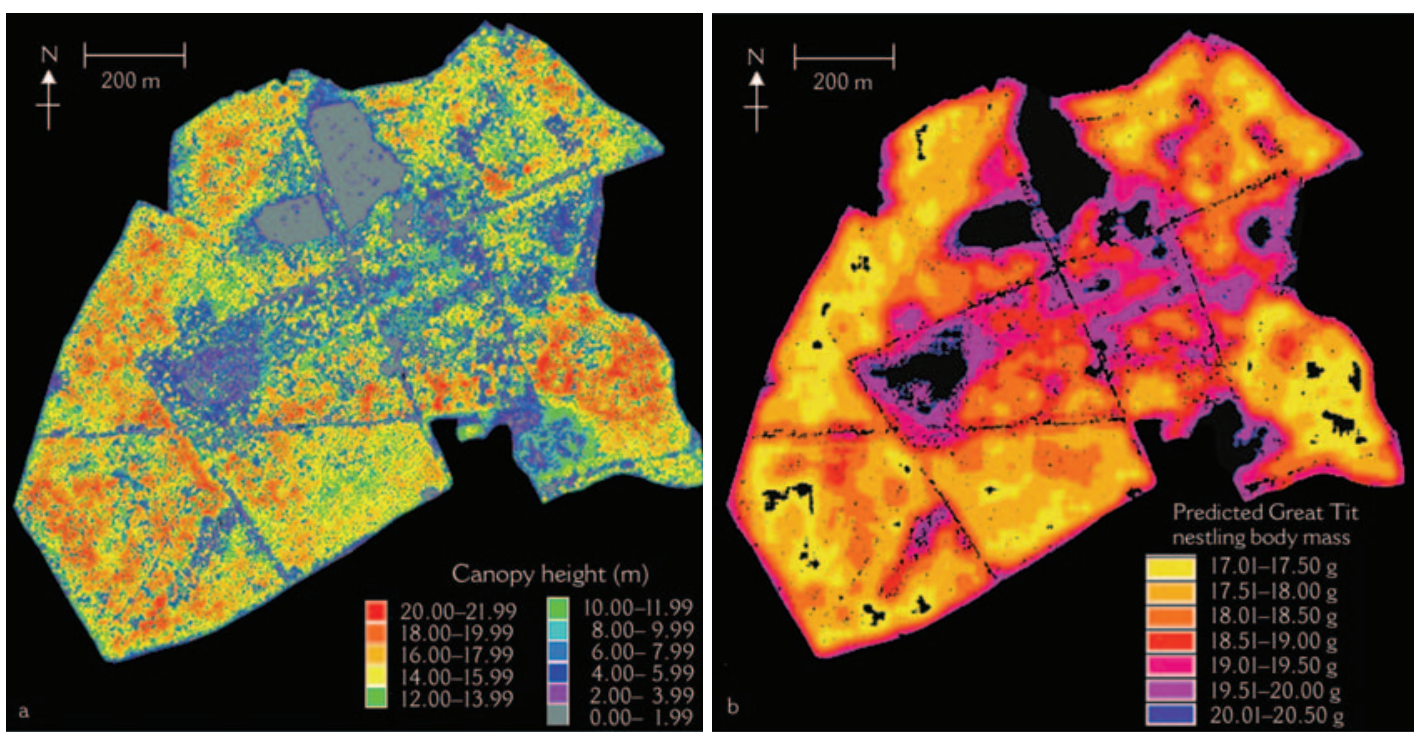

Figure 5 Digital Canopy Height Model of Monks Wood NNR (Cambridgeshire, UK) derived from (a) airborne LiDAR data and (b) predictive map of Great Tit nestling body mass for spring 2001 based on a relationship between nestling body mass and canopy height. Note that areas of Monks Wood NNR with a mean canopy height beyond the range encountered in the sample areas for nestboxes occupied by Great Tits in 2001 were unclassified (shown in black)

Source: Hill et al. (2004).

the role of canopy vertical structure, especially understorey, has been shown to be significant for the distribution of Marsh Tits Poecile palustris across Monks Wood (Broughton et al., 2006). The influence of canopy gaps and tree species composition (especially oak distribution) in addition to canopy height has been demonstrated for Blue Tits and Great Tits, comparing the primary habitat of Monks Wood with the secondary habitat of urban parkland (Hinsley et al., 2008). Structural gaps, and functional gaps generated by variation in the quality of foraging habitat, were shown to increase the energy costs of rearing young. For the Willow Warbler Phylloscopus trochilus at Monks Wood and two additional lowland woodland sites of contrasting management, it has been shown that vegetation height is a key habitat parameter $(<6 \mathrm{~m}$ canopy being preferred) but only where this occurs in patches $>0.5$ ha in size and not along woodland edges (Bellamy et al., 2009).

This body of work has demonstrated the potential of remote sensing to characterize a complex habitat, in terms of spatial and vertical features, and to link this with ecological data to explore and scale up relationships. Habitat quality can be determined by relating remotely sensed metrics to relevant data on ecological processes (such as breeding, foraging, occupancy and survival). Of key significance is capturing heterogeneity both at a fine grain that is relevant to an individual organism and its territory, and at a scale relevant to communities and whole populations. The detailed work reported here is nested within more regional-scale assessments of landscape composition (eg, Fuller et al., 2005).

This example illustrates how the integration of diverse remotely sensed data, 
acquired by different techniques and from different platforms, with ecological field data, facilitates a multiscale and multidimensional approach that can be used to generate testable predictions relating to ecological processes. In addition, this research illustrates that remote sensing technologies can be used to examine vegetation vertical structure and relationships of pattern metrics with landscape topography, through the use of techniques such as LiDAR. In future, the combination of a suite of remotely sensed metrics may enable the assessment of ecological function, and thereby measures of both biodiversity and ecosystem services.

\section{A future research agenda for landscape ecology}

As a discipline, landscape ecology needs to engage more actively with the wide range of remote sensing data and techniques that are available. In addition, there is a need within landscape ecology for greater development and application of theory (Wiens, 1992), while at the same time increasing relevance of the research to human society (Bastian, 2001). Consideration is given below to how these objectives might be achieved in future.

\section{Adopting a more interdisciplinary approach to remote sensing}

A number of reviewers have described the maturation of landscape ecology as a scientific discipline, yet have failed to examine critically the role of remote sensing in its development (Hobbs, 1997; Turner, 2005; Andersen, 2008). For a science that is so dependent on technology, the evidence gathered here highlights a surprising degree of conservatism, at least as far as use of remote sensing methods is concerned. There is clearly scope to extend the number of types of imagery used by landscape ecologists, and to apply remote sensing methods to the many ecosystem types that have been neglected by previous research. Future developments of the discipline should also seek to strengthen its scientific rigour, for example by routinely analysing the implications of uncertainty in image classification for the calculation of landscape pattern metrics (Shao and Wu, 2008).

Interdisciplinary collaboration between landscape ecologists and specialists in remote sensing provides many opportunities for insightful research. An emerging area is the development of iterative workflows in which landscape metrics and classifications are evaluated together. The ability to feed back results derived from the analysis of landscape structure and composition into the classification process can be particularly useful, as this allows the relationship between spectral properties and surface features to be fully explored (Groom et al., 2006). This can lead to the development of improved cartographic products. The capacity to tailor classifications to the needs of the study being undertaken may be particularly useful when the evaluation of habitat quality over a wide landscape is required. The consistency of methods for long-term monitoring of landscape change may be enhanced, along with our understanding of temporal effects at a range of scales, through iterated image classification and landscape analysis (Liang and Schwartz, 2009). A particularly exciting use of remotely sensed data is to enhance understanding of the three-dimensional structure of landscapes though the use of radar or LiDAR.

On the other hand, if these opportunities for interdisciplinary collaboration are overlooked, studies in landscape ecology may be weakened. There are many potential pitfalls (Shao and $\mathrm{Wu}, 2008$ ). Uncertainties involved in image classification might not be considered when landscape metrics are analysed. Confidence intervals may be too narrow and statistical hypothesis tests may produce type one errors (Hess and Bay, 1997; Boots and Csillag, 2006). Scaling effects may be treated naively. For example, shape indices can be extremely sensitive to minor alterations in underlying resolution. The effects of variation in the spatial distribution of classification error may not be fully included. This can 
lead to misleading results. For example, misclassifications that are distributed evenly across a landscape can have a very different impact on landscape metrics than errors that are spatially concentrated (Wickham et al., 1997). The effects of sensor properties, such as spatial and spectral resolution, on the accuracy of the cartographic product might be ignored, even though classifications based on high spatial resolution imagery such as QuickBird and Ikonos can lead to quite different landscape metrics than those derived from medium spatial resolution Landsat imagery.

Most critically, the application of remote sensing in landscape ecology must progress beyond the simplistic approach of thematic mapping and the derivation of two-dimensional pattern metrics. The potential has been demonstrated outside of landscape ecology for remote sensing data to provide a three-dimensional characterization of landscapes and their component parts (eg, Hill et al., 2002). Through the integration of diverse remotely sensed data types and the analyses of time-series data (either intra- or interannual), it has been shown possible to elucidate trends and processes associated with vegetation productivity, health, phenology and fluxes (Gobron et al., 2005; Fang et al., 2008; Liang and Schwartz, 2009), as well as habitat fragmentation and loss (Cakir et al., 2008; Gillanders et al., 2008). Such information combined with the remotely sensed assessment of plant functional types has been fed directly into global climate models, dynamic vegetation models and habitat suitability models (Guisan and Zimmermann, 2000; Fisher et al., 2008; Kooistra et al., 2008). The two case studies presented here, while not unique, exemplify a more sophisticated application of remote sensing data to landscape ecology than has traditionally been the case.

\section{Strengthening the role of theory}

The lack of theory in landscape ecology provides an interesting comparison with the related discipline of metapopulation ecology, in which theoretical developments have played a major role (Hanski, 1999). Although the term 'metapopulation' is now widely applied to a variety of different types of spatially structured population, theoretical developments have tended to focus on development of Levins' 'classic' metapopulation concept (Levins, 1969), aimed at making it more spatially realistic (Hanski, 1998; 2001). Metapopulation theory has provided valuable insights into the impacts of habitat loss and fragmentation, the minimum amount of habitat required for long-term persistence, and predictions of the delay in metapopulation response to habitat loss (the 'extinction debt') (Hanski, 1998; 2004).

Turner (2005) suggests that considerable overlap exists between landscape ecology and metapopulation ecology with respect to objectives and approaches. Some similarities certainly exist: both share a concern with analysing the implications of landscape patterns for ecological processes, and use of the habitat patch concept. However, according to Hanski (1998), the lack of a convincing theoretical framework in landscape ecology is a key difference between the two disciplines. Landscape ecology thus needs a comprehensive underpinning theory.

As noted by Turner (2005), there is now an extensive body of empirical studies that explore ecological responses to landscape patterns. These could be used to develop empirical theory. For example, Harper et al. (2005) and Ries et al. (2004) review research examining the impact of edge effects, enabling the development of predictive models of edge responses, which were tested in one of the case studies presented here (Newton et al., 2009). Reviews of the effects of habitat fragmentation (McGarigal and Cushman, 2002; Fahrig, 2003) similarly provide a basis for development of empirical theory and provide a framework for hypothesis testing (Newton et al., 2009). Such examples highlight how elements of landscape ecology theory could potentially be developed. 
A further approach, as illustrated by the case studies presented here, involves exploration of the impacts of spatial pattern on ecological processes (such as ecological succession) that are underpinned by existing theory.

\section{Relevance to human society}

If landscape ecology should address societal needs (Bastian, 2001), then understanding the causes and effects of environmental change must represent an urgent research priority (Wu and Hobbs, 2002). The development of modelling tools that would enable the impacts of environmental change to be predicted represents a key challenge for ecological and geographical science (Sutherland, 2006). With respect to landscape ecology, models are required that incorporate the processes (or 'pressures') responsible for causing changes in landscape pattern, and enable their potential impacts to be predicted.

A range of different methods are available for modelling environmental pressures, including conceptual models, threat matrices, participatory threat mapping, statistical and rule-based modelling approaches, and process-based models (Newton, 2007a). Such approaches are increasingly being employed to examine the spatial dynamics of processes such as habitat loss and fragmentation, fire, urban expansion and climate change, enabling areas vulnerable to future environmental change to be identified (Wilson et al., 2005). As illustration, Miles et al. (2006) provide an example of integrated spatial analysis of multiple pressures, focusing on the conservation status of tropical dry forests, whereas Barve et al. (2005) provide an example of assessing multiple pressures at the scale of an individual protected area. As noted by Turner (2005), landscape ecologists have employed a wide range of different modelling approaches to explore the processes influencing landscape change, some of which are very sophisticated, such as those used to examine the spatial dynamics of fire (Díaz-Delgado et al., 2004).
Remote sensing techniques could potentially make a major contribution to the development of predictive tools to examine the impacts of environmental change on landscapes. For this potential to be realized, however, there may be a need for a change in perceptions among landscape ecologists regarding the role of remote sensing within the discipline. Rather than purely viewing remote sensing imagery as a tool for mapping landscapes, the many other types of information that can be derived directly from such imagery need to be more widely appreciated, such as measures of ecosystem function (Alcaraz et al., 2006; Zoffoli et al., 2008). There is a particular need to use imagery to analyse the spatial dynamics of environmental pressures, to provide inputs to appropriate models (Newton et al., 2009). Harnessing remote sensing techniques for such applications represents a technical challenge, which is most likely to be successfully addressed through closer collaboration between the landscape ecology and remote sensing research communities.

Analysis of environmental change also requires consideration of its potential impacts, not only on landscape pattern, but on associated ecological processes. Two impacts are currently the focus of particular concern, namely the loss of biodiversity and the associated decline in the provision of ecosystem services. Understanding the potential impact of environmental change on biodiversity requires information on the causes of biodiversity loss, or 'threatening processes' (Balmford et al., 1998), which include changes in landscape pattern such as habitat fragmentation. Again, the development of spatially explicit predictions of the future distribution of threatening processes is required to identify those elements of biodiversity that are particularly vulnerable to environmental change (Wilson et al., 2005). Analytical tools that can be used to develop predictions of potential biodiversity loss include analyses of species-habitat 
relationships (Guisan and Zimmermann, 2000; Elith and Burgman, 2003) and the use of individual-based models of population dynamics (Sutherland, 2006), all of which can potentially be informed by the use of remote sensing imagery.

The concept of ecosystem services has recently been developed to make explicit the connection between human welfare and the state of the environment, to support policy development and implementation (Daily, 1997). This is important because, at present, policy decisions often fail to consider the link between ecosystems and human livelihoods. Recent research suggests that incorporation of ecosystem services into land-use decisions typically favours sustainable management over the conversion of intact ecosystems to other types of land cover (Balmford et al., 2002). However, ecosystem service research is at an early stage of development. Approaches are required for measuring, modelling, mapping and valuing ecosystem services at a range of scales to improve environmental decisionmaking, and to ensure the future well-being of human communities (Balmford et al., 2008). Such analyses need to be dynamic and spatially explicit, again highlighting the need for spatially explicit modelling approaches appropriate for use at a range of scales. There is also a need to integrate insights, methods and data drawn from both natural and social sciences (Balmford et al., 2008). The developing research agenda on ecosystem services therefore coincides closely with that of landscape ecology, since interdisciplinary research approaches have long been considered as a central element of the latter (Wu, 2007), and both also share an interest in ecosystem function.

For analysis of the impacts of environmental change on both biodiversity and ecosystem services, a variety of different models will need to be applied. In this context, a 'toolkit' approach is likely to be most appropriate, involving the integration of existing modelling tools to create 'metamodels' (Sturtevant et al., 2007; Newton et al., 2009). This approach is increasingly being applied to scale up fine-scaled processes to coarser spatial scales. Data derived from remote sensing imagery could provide inputs to such meta-models, and could also provide an analytical framework for their development (Newton et al., 2009). Remote sensing could also be of particular value in providing spatial data on the condition of habitats and ecosystems (Ludwig et al., 2007), in relation to their value as habitat for organisms and their ability to provide services on which human livelihoods depend. Such developments would strengthen the role of remote sensing in environmental monitoring (Groom et al., 2006), both in terms of identifying the impacts of environmental change and the consequences of policy implementation. In this way, further development of remote sensing as a central element of the analytical toolkit for predictive landscape ecology could help realize the potential of both disciplines, both in scientific and societal terms.

\section{Conclusions}

There is a need for closer integration between landscape ecology and remote sensing disciplines. Increased interdisciplinary collaboration between landscape ecologists and specialists in remote sensing would provide new opportunities for insightful research. As illustrated by the case studies presented here, measurable benefits can emerge as a result of a using an iterative workflow in which landscape metrics and classifications are developed and evaluated together. The ability to feed back results derived from the analysis of landscape structure into the classification process is particularly useful, as the relationship between spectral properties and surface features can be explored in depth. Integration with ecological field data leads to the development of improved cartographic products and greater insight into landscape structure and function, as well as analysis of 
uncertainties in derived mapping products and metrics. Also demonstrated is the capacity to progress beyond thematic mapping and the derivation of two-dimensional pattern metrics to provide a three-dimensional characterization of landscapes and their component parts. Further developments that could be integrated into landscape ecology include the derivation of biophysical and biogeochemical variables, environmental pressures and threatening processes as direct inputs to drive environmental change models.

Landscape ecology provides information of considerable societal value. A sound understanding of landscape properties is essential in order to quantify the value of ecosystem services and prioritize areas for biodiversity conservation and management. Increased collaboration between landscape ecologists and specialists in remote sensing will therefore strengthen both the academic and applied value of the discipline of landscape ecology.

\section{Acknowledgements}

This paper was produced with financial support from the European Community's Sixth Framework Programme (FP6), ReForLan project, contract number 032132 . The views presented do not necessarily represent the opinion of the European Community, and the Community is not liable for any use that may be made of the information contained therein. CE acknowledges the financial support of FONDECYT (projects no. 1080408 and 1085877).

\section{References}

Alcaraz, D., Paruelo, J. and Cabello, J. 2006: Identification of current ecosystem functional types in the Iberian Peninsula. Global Ecology and Biogeography 15, 200-12.

Andersen, B.J. 2008: Research in the journal Landscape Ecology, 1987-2005. Landscape Ecology 23, 129-34.

Aplin, P. 2005: Remote sensing: ecology. Progress in Physical Geography 29, 104-13.

Balmford, A., Bruner, A., Cooper, P., Costanza, R., Farber, S., Green, R.E., Jenkins, M., Jefferiss, P., Jessamy, V., Madden, J., Munro, K., Myers, N., Naeem, S., Paavola, J., Rayment, M., Trumper, S. and Turner, R.K. 2002: Economic reasons for conserving wild nature. Science 297, 950-53.

Balmford, A., Mace, G.M. and Ginsberg, J.R. 1998: The challenges to conservation in a changing world: putting processes on the map. In Mace, G.M., Balmford, A. and Ginsberg, J.R., editors, Conservation in a changing world. Conservation biology series 1, Cambridge: Cambridge University Press, 1-28.

Balmford, A., Rodrigues, A.S.L., Walpole, M., ten Brink, P., Kettunen, M., Braat, L. and de Groot, R. 2008: The economics of biodiversity and ecosystems: scoping the science. Cambridge: European Commission, contract: ENV/070307/2007/486089/ ETU/B2.

Barve, N., Kiran, M.C., Vanaraj, G., Aravind, N.A., Rao, D., Uma Shaanker, R., Ganeshaiah, K.N. and Poulsen, J.G. 2005: Measuring and mapping threats to a wildlife sanctuary in southern India. Conservation Biology 19, 122-30.

Bastian, O. 2001: Landscape Ecology - towards a unified discipline? Landscape Ecology 16, 757-66.

Bellamy, P.E., Hill, R.A., Rothery, P., Hinsley, S.A., Fuller, R.J. and Broughton, R.K. 2009: Willow Warbler Phylloscopus trochilus habitat in woods with different structure and management in southern England. Bird Study, in press.

Boots, B. and Csillag, F. 2006: Categorical maps, comparisons, and confidence. Journal of Geographical Systems 8, 109-18.

Bradbury, R.B., Hill, R.A., Mason, D.C., Hinsley, S.A., Wilson, J.D., Balzter, H. , Anderson, Q.A., Whittingham, M.J., Davenport, I.J. and Bellamy, P.E. 2005: Modelling relationships between birds and vegetation structure using airborne LiDAR data: a review with case studies from agricultural and woodland environments. Ibis 147 , 443-52.

Broughton, R. K. , Hinsley, S. A., Bellamy, P.E., Hill, R.A. and Rothery, P. 2006: Marsh Tit Poecile palustris territories in a British broadleaved woodland. Ibis 148, 744-52.

Cakir, G., Sivrikaya, F. and Keles, S. 2008: Forest cover change and fragmentation using Landsat data in Macka State Forest Enterprise in Turkey. Environmental Monitoring and Assessment 137, 51-66.

Cayuela, L., Golicher, D.J. and Rey-Benayas, J.M. 2006a: The extent, distribution and fragmentation of vanishing montane cloud forest in the Highlands of Chiapas, Mexico. Biotropica 38, 544-54.

Cayuela, L., Golicher, D.J., Rey-Benayas, J.M., González-Espinosa, M. and Ramírez-Marcial, N. 2006b: Fragmentation, disturbance and tree diversity conservation in tropical montane forests. Journal of Applied Ecology 43, 1172-82.

Cayuela, L., Golicher, D.J., Salas-Rey, J. and Rey-Benayas, J.M. 2006c: Classification of a complex landscape using Dempster-Shafer theory 
of evidence. International Journal of Remote Sensing 27, 1951-71.

Cayuela, L., Rey Benayas, J.M., Echeverría, C. 2006d: Clearance and fragmentation of tropical montane forests in the Highlands of Chiapas, Mexico (1975-2000). Forest Ecology and Management 226, 208-18.

Cayuela, L., Rey Benayas, J.M., Justel, A., SalasRey J. 2006e: Modelling tree diversity in a highly fragmented tropical montane landscape. Global Ecology and Biogeography 15, 602-13.

Daily, G. 1997: Nature's services: societal dependence on natural ecosystems. Washington, DC: Island Press.

Díaz-Delgado, R., Lloret, F. and Pons, X. 2004: Spatial patterns of fire occurrence in Catalonia, NE, Spain. Landscape Ecology 19, 731-45.

Echeverría, C., Coomes, D., Hall, M. and Newton, A.C. 2008: Spatially explicit models to analyze forest loss and fragmentation between 1976 and 2020 in southern Chile. Ecological Modelling 212, 439-49.

Echeverría, C., Coomes, D., Salas, J., ReyBenayas, J M., Lara, A. and Newton, A.C. 2006: Rapid fragmentation and deforestation of Chilean temperate forests. Biological Conservation 130, 481-94.

Echeverría, C., Newton, A.C., Lara, A., ReyBenayas, J.M. and Coomes, D. 2007: Impacts of forest fragmentation on species composition and forest structure in the temperate landscape of southern Chile. Global Ecology and Biogeography 16, 426-39.

Elith, J. and Burgman, M.A. 2003: Habitat models for population viability analysis. In Brigham, C.A. and Schwartz, M.A., editors, Population viability in plants. Conservation, management and modeling of rare plants, Ecological Studies 165, Berlin: SpringerVerlag, 203-35.

Fahrig, L. 2003: Effects of habitat fragmentation on biodiversity. Annual Review of Ecology, Evolution and Systematics 34, 487-515.

Fang, H.L., Liang, S.L., Townshend, J.R. and Dickinson, R.E. 2008: Spatially and temporally continuous LAI data sets based on an integrated filtering method: examples from North America. Remote Sensing of Environment 112, 75-93.

Fisher, J.B., Tu, K.P. and Baldocchi, D.D. 2008: Global estimates of the land-atmosphere water flux based on monthly AVHRR and ISLSCP-II data, validated at 16 FLUXNET sites. Remote Sensing of Environment 112, 901-19.

Forman, R.T.T. 1995: Some general principles of landscape and regional ecology. Landscape Ecology 10, 133-42.

Frohn, R.C. 1998: Remote sensing for landscape ecology: new metric indicators for monitoring, modeling, and assessment of ecosystems. Boca Raton, FL: CRC Press.
Fuller, R.M., Devereux, B.J., Gillings, S., Amable, G.S. and Hill, R.A. 2005: Indices of bird-habitat preference from bird field surveys and remote sensing of land cover: a study of south-eastern England with wider implications for conservation and biodiversity assessment. Global Ecology and Biogeography 14, 223-39.

Gaveau, D.L.A. and Hill, R.A. 2003: Quantifying canopy height underestimation by laser pulse penetration in small-footprint airborne laser scanning data. Canadian Journal of Remote Sensing 29, 650-57.

Gillanders, S.N., Coops, N.C., Wulder, M.A., Gergel, S.E. and Nelson, T. 2008: Multitemporal remote sensing of landscape dynamics and pattern change: describing natural and anthropogenic trends. Progress in Physical Geography 32, 503-28.

Gobron, N., Pinty, B., Melin, F., Taberner, M., Verstrate, M.M., Belward, A., Lavergne, T. and Widlowski, J.L. 2005: The stae of vegetation in Europe following the 2003 drought. International Journal of Remote Sensing 26, 2013-20.

Golicher, D.J., Cayuela, L., Alkemade, J.R.M., Gonzalez-Espinosa, M. and Ramirez-Marcial, N. 2008: Applying climatically associated species pools to the modelling of compositional change in tropical montane forests. Global Ecology and Biogeography 17, 262-73.

Groom, G., Mücher, C.A., Ihse, M. and Wrbka, T. 2006: Remote sensing in landscape ecology: experiences and perspectives in a European context. Landscape Ecology 21, 391-408.

Guisan, A. and Zimmermann, N.E. 2000: Predictive habitat distribution models in ecology. Ecological Modelling 135, 147-86.

Hanski, I. 1998: Metapopulation dynamics. Nature 396, 41-49.

- 1999: Metapopulation ecology. Oxford: Oxford University Press.

- 2001: Spatially realistic theory of metapopulation ecology. Naturwissenschaften 88, 372-81.

- 2004: Metapopulation theory, its use and misuse. Basic and Applied Ecology 5, 225-29.

Harper, K.A., MacDonald, E.S., Burton, P.J., Chen, J., Brosofske, K.D., Saunders, S.C., Euskirchen, E.S., Roberts, D., Jaiteh, M.S. and Esseen, P.-A. 2005: Edge influence on forest structure and composition in fragmented landscapes. Conservation Biology 19, 768-82.

Hess, G.R. and Bay, J.M. 1997: Generating confidence intervals for composition-based landscape indexes. Landscape Ecology 12, 309-20.

Hill, R.A. and Broughton, R.K. 2009: Mapping understorey from leaf-on and leaf-off airborne LiDAR data of deciduous woodland. ISPRS Journal of Photogrammetry and Remote Sensing 64, 223-33. 
Hill, R.A. and Thomson, A.G. 2005: Mapping woodland species composition and structure using airborne spectral and LiDAR data. International Journal of Remote Sensing 26, 3763-79.

Hill, R.A., George, M. and Wilson, A.K. 2008: Mapping deciduous tree species in time-series ATM data based on differential rates of green-up and senescence. In Proceedings of the Remote Sensing and Photogrammetry Society (RSPSoc) Annual Conference, Falmouth, 15-17 September, 4 pp (on CD-ROM).

Hill, R.A., Hinsley, S.A., Gaveau, D.L.A. and Bellamy, P.E. 2004: Predicting habitat quality for Great Tits (Parus major) with airborne laser scanning data. International Journal of Remote Sensing 25, 4851-55.

Hill, R.A., Smith, G.M., Fuller, R.M. and Veitch, N. 2002: Landscape modelling using integrated airborne multi-spectral and elevation data. International Journal of Remote Sensing 23, 2327-34.

Hinsley, S.A., Hill, R.A., Bellamy, P.E. and Baltzer, H. 2006: The application of LiDAR in woodland bird ecology: climate, canopy structure and habitat quality. Photogrammetric Engineering and Remote Sensing 72, 1399-406.

Hinsley, S.A., Hill, R.A., Bellamy, P.E., Harrison, N.M., Speakman, J.R., Wilson, A.K. and Ferns, P.N. 2008: Effects of structural and functional habitat gaps on woodland birds: working harder for less. Landscape Ecology 23, 615-26.

Hinsley, S.A., Hill, R.A., Fuller, R.J., Bellamy, P.E. and Rothery, P. 2009: Bird species distributions across woodland canopy structure gradients. Community Ecology 10, 99-110.

Hinsley, S.A., Hill, R.A., Gaveau, D.L.A. and Bellamy, P.E. 2002: Quantifying woodland structure and habitat quality for birds using airborne laser scanning. Functional Ecology 16, 851-57.

Hobbs, R. 1997: Future landscapes and the future of landscape ecology. Landscape and Urban Planning $37,1-9$.

Iverson, L. 2007: Adequate data of known accuracy are critical to advancing the field of landscape ecology. In Wu, J. and Hobbs, R., editors, Key topics in landscape ecology, Cambridge: Cambridge University Press, 11-38.

Kooistra, L., Wamelink, W., Schaepman-Strub, G., Schaepman, M., van Dobben, H., Aduaka, U. and Batelaan, O. 2008: Assessing and predicting biodiversity in a floodplain system: assimilation of net primary production derived from imaging spectrometer data into a dynamic vegetation model. Remote Sensing of Environment 112, 2118-30.

Levins, R. 1969: Some demographic and genetic consequences of environmental heterogeneity for biological control. Bulletin of the Entomological Society of America 15, 237-40.
Liang, L. and Schwartz, M.D. 2009: Landscape phenology: an integrative approach to seasonal vegetation dynamics. Landscape Ecology 24, 465-72.

Ludwig, J.A., Bastin, G.N., Wallace, J.F. and McVicar, T.R. 2007: Assessing landscape health by scaling with remote sensing: when is it not enough? Landscape Ecology 22, 163-69.

McDermid, G.J., Franklin, S.E. and LeDrew, E.F. 2005: Remote sensing for large-area habitat mapping. Progress in Physical Geography 29, 449-74.

McGarigal, K. and Cushman, S.A. 2002: Comparative evaluation of experimental approaches to the study of habitat fragmentation effects. Ecological Applications 12, 335-45.

Miles, L., Newton, A.C., DeFries, R., Kapos, V., Blyth, S. and Gordon, J. 2006: A global overview of the conservation status of tropical dry forests. Journal of Biogeography 33, 491-505.

Muchoney, D.M. 2008: Earth observations for terrestrial biodiversity and ecosystems. Remote Sensing of Environment (special issue) 112, 1905-11.

Newton, A.C. 2007a: Forest ecology and conservation: a handbook of techniques. Oxford: Oxford University Press.

-, editor) 2007b: Biodiversity loss and conservation in fragmented forest landscapes. The forests of montane Mexico and temperate South America. Wallingford, Oxford: CABI Publishing.

- 2008: Restoration of dryland forest in Latin America: the ReForLan project. Ecological Restoration 26, 10-13.

Newton, A.C., Cayuela, L., Echeverría, C., Armesto, J.J., Del Castillo, R.F., Golicher, D., Gonzalez-Espinosa, M., Huth A., Lara, A., López-Barrera, F., Manson, R., Premoli, A.C., Ramírez-Marcial, N., Rey Benayas, J.M., Rüger, N., Smith-Ramírez, C. and WilliamsLinera, G. 2009: Towards integrated analysis of human impacts on forest biodiversity: lessons from Latin America. Ecology and Society 14(2), 2. Retrieved 13 September 2009 from http://www. ecologyandsociety.org/voll4/iss2/art2

Patenaude, G., Hill, R.A., Milne, R., Gaveau, D.L.A., Briggs, B.B.J. and Dawson, T.P. 2004: Quantifying forest above ground carbon content using LiDAR remote sensing. Remote Sensing of Environment 93, 368-80.

Ries, L., Fletcher, R.J., Battin, J. and Sisk, T.D. 2004: Ecological responses to habitat edges: mechanisms, models, and variability explained. Annual Review of Ecology, Evolution and Systematics 35, 491-522.

Shao, G. and $\mathbf{W u}$, J. 2008: On the accuracy of landscape pattern analysis using remote sensing data. Landscape Ecology 23, 505-11.

Sturtevant, B.R., Fall, A., Kneeshaw, D.D., Simon, N.P.P., Papaik, M.J., Berninger, K., 
Doyon, F., Morgan, D.G. and Messier, C. 2007: A toolkit modeling approach for sustainable forest management planning: achieving balance between science and local needs. Ecology and Society 12(2), 7. Retrieved 19 August 2009 from http://www. ecologyandsociety.org/voll2/iss2/art7

Sutherland, W.J. 2006: Predicting the ecological consequences of environmental change: a review of the methods. Journal of Applied Ecology 43, 599-616.

Turner, M.G. 2005: Landscape ecology: what is the state of the science? Annual Review of Ecology, Evolution and Systematics 36, 319-44.

Turner, M.G., Gardner, R.H. and O'Neill, R.V. 2001: Landscape ecology in theory and practice. New York: Springer.

Turner, W., Spector, S., Gardiner, N., Fladeland, M., Sterling, E. and Steininger, M. 2003: Remote sensing for biodiversity science and conservation. Trends in Ecology and Evolution 18, 306-14.

Wickham, J.D., O'Neill, R.V., Riitters, K.H., Wade, T.G. and Jones, K.B. 1997: Sensitivity of selected landscape pattern metrics to land-cover misclassification and differences in land-cover composition. Photogrammetric Engineering and Remote Sensing 63, 397-402.
Wiens, J.A. 1992: What is landscape ecology, really? Landscape Ecology 7, 149-50.

Wilson, K., Pressey, R.L., Newton, A., Burgman, M., Possingham, H. and Weston, C. 2005: Measuring and incorporating vulnerability into conservation planning. Environmental Management 35, 527-43.

Wu, J. 2006: Cross-disciplinarity, landscape ecology, and sustainability science. Landscape Ecology 21, $1-4$.

- 2007: Past, present and future of landscape ecology. Landscape Ecology 22, 1433-35.

Wu, J. and Hobbs, R. 2002: Key issues and research priorities in landscape ecology: an idiosyncratic synthesis. Landscape Ecology 17, 355-65.

-, editors 2007: Key topics in landscape ecology. Cambridge: Cambridge University Press.

Wulder, M.A. and Franklin, S.E., editors 2003: Remote sensing of forest environments: concepts and case studies. Dordrecht: Kluwer.

Zoffoli, M.L., Kandus, P., Madanes, N. and Calvo, D.H. 2008: Seasonal and interannual analysis of wetlands in South America using NOAA-AVHRR NDVI time series: the case of the Parana Delta Region. Landscape Ecology 23, 833-48. 